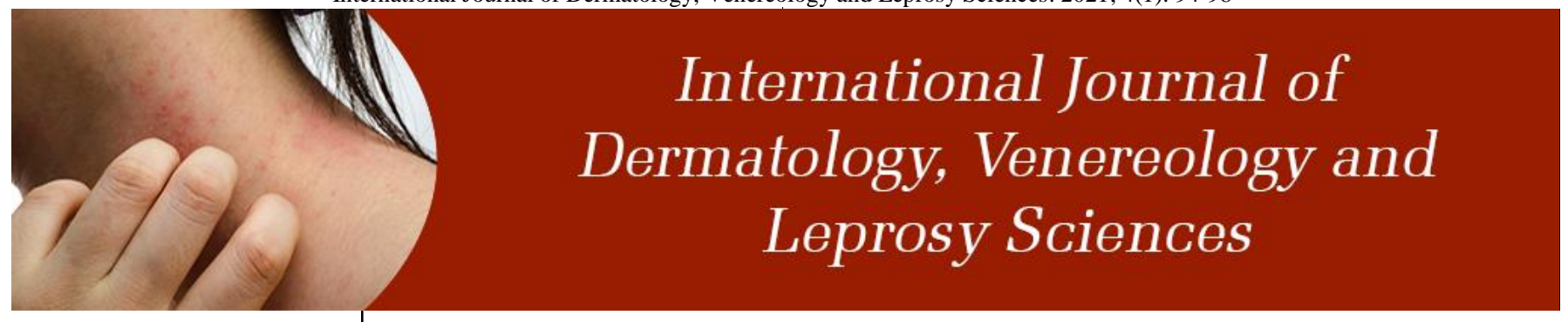

E-ISSN: 2664-942X

P-ISSN: 2664-9411

www.dermatologypaper.com

Derma 2021; 4(1): 94-98

Received: 20-11-2020

Accepted: 25-12-2020

Purnachandra Badabagni Associate Professor,

Department of Dermatology,

Venereology \& Leprosy, ESIC

Medical College and Hospital,

Hyderabad, Telangana, India

Ramadevi Birudala

Assistant Professor,

Department of Dermatology,

Venereology \& Leprosy,

Kamineni Academy of Medical

Sciences and Research Center,

LB Nagar, Hyderabad,

Telangana, India
Corresponding Author:

Ramadevi Birudala

Assistant Professor,

Department of Dermatology,

Venereology \& Leprosy,

Kamineni Academy of Medical Sciences and Research Center,

LB Nagar, Hyderabad,

Telangana, India

\section{A comparative study of $35 \%$ glycolic acid peel versus modified Kligman's regimen in treating Melasma in patients with dark skin}

\author{
Purnachandra Badabagni and Ramadevi Birudala
}

DOI: https://doi.org/10.33545/26649411.2021.v4.i1b.74

\begin{abstract}
Introduction: Melasma is the most common cause of facial Melanesia classically presenting as hyper pigmented macules to patches on the face causing great psychological stress. The pathogenicity of it is not yet completely understood. Many treatment options are available but nothing is satisfactory, especially in black patients. The study aims to compare the serial 35\% Glycolic Acid (GA) Peels versus a topical modified Kligman's regimen in treating Melasma in patients with dark skin.

Materials and methods: Prospective and comparative study was done on 100 cases of Melasma, dividing them into two groups with 50 patients each. One group received topical modified Kligman's formula (MKF) daily and the other group received 35\% glycolic acid peels once in 4weeks for 12 weeks. Response was assessed by MASI score.

Results: At the end of 12 weeks good to very good response was seen i.e. 95\% on MKF treated patients where as $85 \%$ on glycolic acid peel patients. Burning sensation and redness was observed in many patients in glycolic acid group whereas cuneiform eruptions in MKF group.

Conclusion: Both glycolic acid peels and modified Kligman's formula are effective in treating Melasma in dark skinned patients both used in combination gives an accelerated response.
\end{abstract}

Keywords: Melasma, Glycolic acid peel, Modified Kligman's formula

\section{Introduction}

Melasma (Greek: Melas = black) is a common acquired Hypermelanosis that typically affects sun exposed areas mainly the forehead, cheeks, temples, nose, upper lips $\&$ chin and occasionally over the forearms \& V area of neck ${ }^{[1]}$. It is clinically presents as medium to dark brown macules to patches with definite borders.

Melasma can be seen in all races \& ethnic groups. People with darker skini.eFitzpatrick IV$\mathrm{V}$ skin types, ${ }^{[2]}$ are prone to get Melasma and more common in those residing in places of high intensity of UV radiation. It mostly affects women (more than 90\%) of child bearing age ${ }^{[3]}$.

Based on distribution on face, ${ }^{[3]}$ clinical patterns Centro facial, Malar and Mandibular are seen. A rare pattern localized to forearms is observed in women taking progesterone exogenously. The Centro facial pattern is the most common seen in nearly $2 / 3$ rd cases of Melasma ${ }^{[4]}$ but malar type is commoner in dark skinned individuals. ${ }^{5}$ Based on woods lamp examination, Melasma is classified into four types. They are Epidermal, Dermal, Mixed and Indeterminate ${ }^{[2]}$.

The precise cause of Melasma remains elusive. Genetic predisposition, exposure to sunlight, pregnancy, oral contraceptive use, endocrine dysfunction, hormonal treatment (estrogen progesterone therapy), cosmetics usage, phototoxic and antiepileptic medication are all the triggering agents.

Melasma is difficult to manage as it is recurrent and resistant. Therapies have included various combinations of topical hydroquinone, corticosteroids, retinoid, atelic acid 15-20\%, Kojic acid, glycolic acid, Arbitron etc ${ }^{[6]}$ and chemical peeling using alpha Hydroxy acids and lasers. Despite many options, treating Melasma is very difficult \& frustrating both for the dermatologist and the patient. ${ }^{7}$

Kligman's formula, which is a combination of dexamethasone $0.1 \%$ (steroid), $0.1 \%$ retinoid and hydroquinone $5 \%$ in a cream base has been in use for more than 2 decades for the 
treatment of melasma ${ }^{[8]}$. Later several modifications done and one among them includes $4 \%$ hydroquinone, $0.05 \%$ retinoid and $1 \%$ hydrocortisone acetate. Hydroquinone is most commonly prescribed bleaching agent. Retinoic facilitates pigment removal by accelerating keratinocyte turn over and enhancing hydroquinone penetration whereas corticosteroid reduces inflammation caused by both hydroquinone and retinoid ${ }^{[9]}$.

Chemical peeling with Glycolic acid which is a $\alpha$ Hydroxy acid improves skin appearance by exfoliating part or entire epidermis and its subsequent resurfacing. Deposition of glycosaminoglycan's in dermis leads to remodel collagen and elastin fibers which in turn improves skin texture. ${ }^{10}$

In general, Melasma of short duration shows better response compared to longstanding cases and in the epidermal type of Melasma faster response is seen than the dermal and mixed type ${ }^{[11]}$.

\section{Materials and methods}

The present study is a Prospective and Comparative study which includes 100 patients, attending a tertiary care hospital in south India. Duration of the study is one year from January 2019 to December 2019. Approval is taken from the ethical committee.

All patients diagnosed to have Melasma attending the Dermatology OPD at ESIC medical college Hospital, Hyderabad were included in this study. Patients with history of known hypersensitivity to Glycolic acid, Hydroquinone, Retinoic, active herpes simplex, warts, moll scum contagious, Keloidal tendency or unrealistic expectations were excluded; Pregnant and breast feeding women were not taken into this study. Skin diseases like atopic or seborrhea dermatitis, psoriasis, perioral dermatitis were first treated and controlled and later taken into study.

100 patients were recruited into two groups, each having 50. First group received modified Kligman's formula (Hydroquinone-4\%, Tretinoin-0.05\%, Hydrocortisone acetate-1\%) daily and the second group received $35 \%$ glycolic acid peels serially once in 4 weeks for a period of 12 weeks. The history in detail, including demographic data, onset, disease duration, progression, triggering factors, other associated systemic illness, family history, past treatment history were recorded in the proforma. The area to be peeled was examined, paying attention to the tone, texture and quality of the skin. Clinical response is assessed by taking photographs before starting the therapy and then at every visit. A written informed consent was taken prior to application.
Response was assessed by MASI score, clinical photographs, and subjective assessment by the patient, clinical assessment (size and depth of pigmentation). All patients were advised sun protection strictly and to apply broad spectrum sunscreen during the study period.

Masi Score: ${ }^{[12]}$

Total MASI score: Forehead $0.3(\mathrm{D}+\mathrm{H}) \mathrm{A}+$ right malar 0.3 $(\mathrm{D}+\mathrm{H}) \mathrm{A}+$ left malar $0.3(\mathrm{D}+\mathrm{H}) \mathrm{A}+\operatorname{chin} 0.1(\mathrm{D}+\mathrm{H}) \mathrm{A}$.

$\mathrm{D}$ is darkness graded from 0 to $4, \mathrm{H}$ is homogeneity graded from 0 to 4 , $\mathrm{A}$ is percentage area of the face affected graded from 0 to 6 .

\section{Results}

In the present study of 100 cases of Melasma, the age of the patients ranged from 14-55 years and the mean age was 31.54 years. Most of the patients $(82 \%)$ were in third and fourth decades. Predominance of females (64\%) was observed.

Table 1: Clinical types of Melasma $(\mathrm{N}=100)$

\begin{tabular}{|c|c|c|}
\hline S.No & Age (Years) & No. of Cases (\%) \\
\hline 1. & Malar & $75(75 \%)$ \\
\hline 2. & Centro facial & $25(25 \%)$ \\
\hline
\end{tabular}

Most of the patients $(75 \%)$ had malar type.

Table 2: Precipitating factors in Melasma ( $\mathrm{N}=100)$

\begin{tabular}{|c|c|c|}
\hline S.No & Factors & No. of Patients (\%) \\
\hline 1 & Sun Exposure & $57(57 \%)$ \\
\hline 2 & Pregnancy & $20(20.0 \%)$ \\
\hline 3 & Drugs & $10(10 \%)$ \\
\hline 4 & Cosmetics & $3(3 \%)$ \\
\hline 5 & Idiopathic & $10(10 \%)$ \\
\hline
\end{tabular}

The main precipitating factor accounting for $57 \%$ was the sun exposure, followed by pregnancy $(20 \%)$ and drugs (10\%). Drugs implicated were mostly Oral Contraceptive pills and Phenytoin in 2 patients. However multiple factors were involved in causation of Melasma in $35 \%$ of patients (table 2).

Table 3: Disease Duration in Melasma $(\mathrm{N}=100)$

\begin{tabular}{|c|c|c|}
\hline S.No & Duration of the Disease in Years & No. of Patients (\%) \\
\hline 1 & $<0.5$ & $9(9 \%)$ \\
\hline 2 & $>0.5-1$ & $22(22 \%)$ \\
\hline 3 & $>1-3$ & $42(42 \%)$ \\
\hline 4 & $>3-10$ & $24(24 \%)$ \\
\hline 5 & $>10$ & $3(3 \%)$ \\
\hline
\end{tabular}

$73 \%$ of the patients had disease duration up to 3 years

Table 4: Comparison of Mean MASI Scores

\begin{tabular}{|c|c|c|c|c|}
\hline Period & $\begin{array}{l}\text { Modified Kligman's formula }(\mathbf{N}=50) \\
\text { Mean score (S.D) }\end{array}$ & $\begin{array}{l}\text { Glycolic acid }(\mathbf{N}=50) \\
\text { Mean score }(\text { S.D) }\end{array}$ & $\mathbf{Z}$ value & $P$ value \\
\hline Pre treatment & $10.87(3.15)$ & $8.14(2.92)$ & 0.847 & $>0.05$ \\
\hline Post treatment MASI (12 weeks) & $3.04(1.41)$ & $2.96(1.12)$ & 7.06 & $<0.05$ \\
\hline Difference between pretreatment and post peel & $7.83(1.74)$ & $5.18(1.80)$ & 10.48 & $<0.05$ \\
\hline
\end{tabular}

From table 4, the mean MASI score decreased after treatment in the two groups, but more on MKF group and is found to be statistically significant.
The mean percentage improvement in MASI score was $71.43 \%$ in MKF group and $62.68 \%$ in GA group.

Table 5: Clinical Response in Melasma

\begin{tabular}{|c|c|c|c|c|}
\hline S.No & Grade of Improvement & Percentage decrease in MASI at end of 4 peels & MKF No of cases (\%) & GA No of cases (\%) \\
\hline 1 & Mild & up to 25 & - & $2(5 \%)$ \\
\hline 2 & Moderate & $26-50$ & $2(5 \%)$ & $5(10 \%)$ \\
\hline
\end{tabular}




\begin{tabular}{|c|c|c|c|c|}
\hline 3 & Good & $51-75$ & $13(25 \%)$ & $18(35 \%)$ \\
\hline 4 & Very good & $>75$ & $35(70 \%)$ & $25(50 \%)$ \\
\hline
\end{tabular}

Good to very good response was seen in $95 \%$ on MKF treated patients

Good to very good response was seen in $85 \%$ on GA treated patients

Table 6: Response in Relation to duration of disease $(\mathrm{N}=50)$

\begin{tabular}{|c|c|c|c|c|c|c|c|c|c|}
\hline \multirow[t]{2}{*}{ S.No } & \multirow[t]{2}{*}{ Duration of disease } & \multicolumn{4}{|c|}{ Response to MKF } & \multicolumn{4}{|c|}{ Response to GA } \\
\hline & & Mild & Moderate & Good & Very good & Mild & Moderate & Good & Very good \\
\hline 1 & $<6$ months & - & - & & 5 & - & - & - & 4 \\
\hline 2 & 6 months -1 year & - & - & 1 & 10 & - & - & 3 & 9 \\
\hline 3 & $>1-3$ years & - & & 5 & 16 & - & 1 & 9 & 10 \\
\hline 4 & $>3-10$ years & & 1 & 7 & 4 & - & 4 & 6 & 2 \\
\hline 5 & $>10$ years & & 1 & - & - & 2 & - & - & - \\
\hline
\end{tabular}

Response to treatment is better with shorter duration of disease ( $<3$ years) i.e in $73 \%$ of cases and is found to be statistically significant $(\mathrm{p}<0.05)$. Good to very good response is seen in short duration of disease i.e 1-3 years where as only mild response is seen in long duration of disease i.e $>10$ years with both MKF and GA peel.

Table 7: Frequency of side effects in GA Vs MKF treated patients $(\mathrm{N}=100)$

\begin{tabular}{|c|c|c|}
\hline Side effects & Glycolic Acid & MKF \\
\hline Burning sensation & $42(85.0 \%)$ & - \\
\hline Erythema & $19(40.0 \%)$ & $5(10 \%)$ \\
\hline Cuneiform eruption & - & $10(20 \%)$ \\
\hline Itching & $3(5.0 \%)$ & $3(5.0 \%)$ \\
\hline Hypertrichosis & $1(2 \%)$ & $2(4 \%)$ \\
\hline
\end{tabular}

Burning sensation and erythema was observed in most of the patients in glycolic acid group and cuneiform eruptions were seen in most cases in MKF group.

\section{Discussion}

Melasma is one of the pigmentary disorders of greatest concern for the patients particularly in females. Despite having many treatment modalities, the treatment of Melasma is not satisfactory but also disappointing and unsuccessful.

100 patients with Melasma over face attended the dermatology department in the ESI medical college were included in the study.

In this study mean age of onset is 31.54 years which is similar to studies done by Griffiths CEM et al. ${ }^{[13]}$, Kalla et $a l^{\left[{ }^{[14]}\right.}$ and Javaheri et al. ${ }^{[15]}$ with average age of 30 years of onset. A study done by Ameen Basil et al. ${ }^{[16]}$ showed an average of 39 years at onset. Female preponderance (64\% is seen) which is similar to studies done by Ravali et al. ${ }^{[17]}$, Nanda et al. ${ }^{[18]}$ and Ameen Basil et al. Preponderance is mainly attributed to hormonal factors.

$75 \%$ of patients showed malar paten followed by Centro facial pattern with $25 \%$, which is similar to Ravali et al. ${ }^{[17]}$, Ameen Basil et al. ${ }^{[16]}$ where malar pattern is seen in $68 \%$ and $42 \%$ respectively. In contrast, Centro facial was predominant in studies done by Griffiths CEM et al. [13] Grover and Reddy et al. [19] variable results could be because of different sample sizes.

In the present study, the main precipitating factor is sun exposure $(57 \%)$ followed by pregnancy $(20 \%)$, drugs (10\%) idiopathic (10\%), and cosmetics (3\%). Drugs implicated are OC pills (8 patients), phenytoin (2 patients). However multiple factors were involved in causation of Melasma in $35 \%$ of patients. Variable results may be because of the rural background of the patients and most of them being agricultural workers.
Wood's lamp examination although used in this study, it was not of much help as most of the patients were of skin type 3 - 6and hence differentiation of depth was not perceptible. Therefore no grading of Melasma on the basis of depth was done in this study. Lawrence et al. ${ }^{[20]}$ showed that wood's lamp is not helpful to assess the response to treatment. However assessment of pigmentation was done on clinical grounds, MASI scoring and photo documentation.

In the present study, response to treatment was better in patients having shorter duration of disease ( $<3$ years) in both the groups. In patients with long duration of disease, response with MKF was more as compared to glycolic acid peel. Similar results were found in other studies ${ }^{[21]}$.

In the present study, the decrease in MASI score was compared with the scores before beginning the study i.e pretreatment scores. In the two groups the MASI scores were reduced. The total clinical and therapeutic response based on percentage decrease in mean MASI scores and grades of improvement, was observed better in MKF group and was found to be statistically significant. $(\mathrm{p}<0.05)$.

In the present study, most of the patients under GA group complained of burning sensation and redness (erythema) whereas cuneiform eruptions were observed in patients of GA group. This observation is in concordance with other studies done by Bari AU et al. ${ }^{[22]}$ and Gupta RR et al. ${ }^{[23]}$. Hypertrichosis was observed in both the sides. This may be due to the counter irritant effect of the peeling agents.

Allergic sensitization, hypochromic of normal skin and post inflammatory hyper pigmentation were not encountered in any of our patients. No systemic side effects were recorded. None of the side effects interfered with the peeling process in any patient. This finding is in concordance with the study done by Bari AU et al. ${ }^{[22]}$.

Follow up in this study was done for 2 months. The relapse rate was $5 \%$ in MKF group. No relapse was found in GA group. This finding is similar to the study done by Kalla et al. ${ }^{[14]}$, Javaheri et al. ${ }^{[15]}$ and Sarkar et al. ${ }^{[24]}$.

\section{Conclusion}

The present study shown that the total clinical and therapeutic response at the end of the study was better on MKF group compared to GA group and the analysis was found to be statistically significant $(p<0.05)$. The response to treatment was better with shorter duration of disease. Side effects were minimal and did not interfere with therapy. Relapse was observed in very few cases of MKF group. The clinical response can be accelerated when superficial glycolic acid peel is used in combination with topical therapy in treating Melasma with patients with dark skin. 


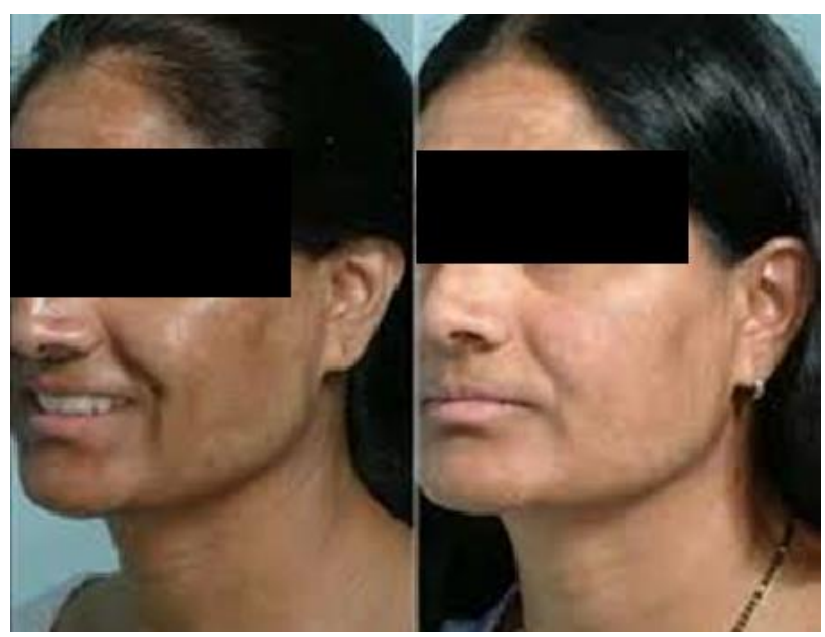

Fig 1: Response after treating with MKF regimen

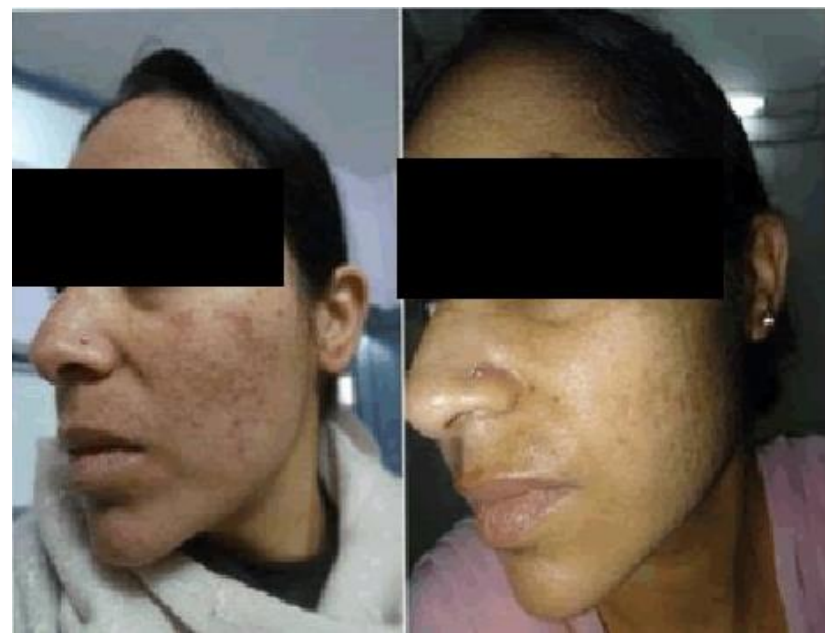

Fig 2: Response after treating with MKF regimen
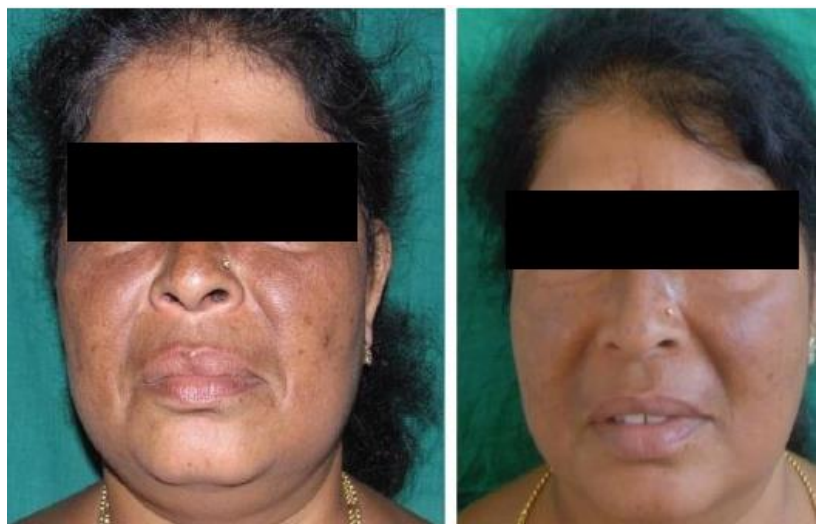

Fig 3: Response after treatment with glycolic acid peel

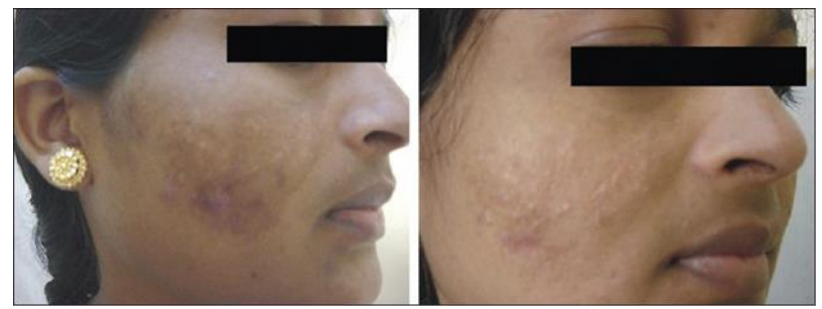

Fig 4: Response after treatment with glycolic acid peel

\section{References}

1. Grimes PE, Melasma. Etiologic and therapeutic considerations Arch Dermatol. 1995; 131:1453-7.
2. Sarkar R, Arora P, Garg VK, Sonthalia S, Gokhale N. Melasma update Indian Dermatol Online J. 2014; 5:426-35.

3. Rendon M, Bemeburg M, Arellano I. et al. Treatment of Melasma J Am Acad Dermatol 2006; 54:S2272S2281.

4. Heather Woolery Lloyd, M.D Rising to the Melasma Treatment challenge, Journal of skin and aging: 2003; 11:3.

5. Bhor U, Pande S. Scoring systems in dermatology. Indian J DermatoI Venerol Leprol. 2006; 72:315.

6. Perez Bernal A. Management of facial hyperpigmentation Am J Clin Dermatol. 2000; 1:216.

7. Tian E. Topical treatment of melasma. NSC Bulletin for Medical Practitioners, 1994, 5.

8. Katambas A, Antoniou CH, Melasma Clinical classification and treatment, J Eur Acad Dermatol Venereol. 1995; 4:217-23.

9. Godse KV. Triple combination of hydroquinone, tretinoin and mometasone furoate with glycolic acid peels in Melasma, Indian J Dermatol. 2009; 54(1):9293.

10. Savant SS, Mehta N. Superficial and Medium Depth Chemical Peeling, in: Savant SS, Shah RA, Gore Deds. Textbook and Atlas of Derma to surgery and cosmetology 1 stedn. Mumbai ASCAD, 1998, 136-14.

11. Taylor SC. Epidemiology of skin diseases in people of color Cutisl. 2003; 21:275

12. Mahajan R, Kanwar AJ, Parsad D, Kumaran MS, Sharma R. Glycolic acid peels/azelaic acid $20 \%$ cream combination and low potency triple combination lead to similar reduction in Melasma severity in ethnic skin: Results of a randomized controlled study. Indian $\mathbf{J}$ Dermatol. 2015;60:147-52

13. Griffiths CE, Finkel LT. Ditre CM et al. Topical tretinoin (retinoic acid) improves Melasma: A vehicle controlled clinical trial Br. J. Dermatol. 1993; 129:41521.

14. Kalla G Anush Garg, Kacchwa D. Chemical peeling GA versus TCA in Melasma, In cosmetology, IJDVL. 2001; 67:82-84.

15. Javaheri SM, Handa S, Kaur I, Kumar B. Safety and efficacy of glycolic acid facial peel in Indian women with Melasma, Int J Dermatol. 2001; 40(5):354-7.

16. Basil A, Akula M L, Najmuddin F, Shetty N J, Shetty M, A comparative study between the efficacy of $35 \%$ glycolic acid peel and triple combination cream in the treatment of Melasma, IP Indian J Clin Exp Dermatol. 2018; 4(2):123-131.

17. Yalamanchili R, Shastry V, Betkerur J. Clinicoepidemiological study and quality of life assessment in melasma. Indian J Dermatol. 2015; 60:519.

18. Nanda S, Grover C, SN Reddy B. Efficacy of hydroquinone $(2 \%)$ versus Tretinoin $(0.025 \%)$ as adjunct topical agents for chemical peeling in patients of Melasma, Dermatol Surg. 2004; 30:3-386.

19. Grover C, Reddy BS. The therapeutic value of glycolic acid peels in dermatology. Indian J Dermatol Venereol Leprol. 2003; 69:148-50.

20. Naomi Lawrence, Sue Ellen Cox, and Harold J. Brody. Treatment of Melasma with Jessner's solution versus glycolic acid: A comparison of clinical efficacy and evaluation of the predictive ability of wood's light examination, J. Am Acad Dermatol. 1997; 36:589-593. 
21. Im S. Increased expression of a melanocyte stimulating hormone in the lesion skin of Melasma, Br J Dermatol. 2002; 146:165.

22. Bari AU, Iqbal Z, Rahman SB. Tolerance and safety of superficial chemical peeling with salicylic acid in various facial dermatomes, Indian J Dermatol Venereol Leprol. 2005; 71:87-90.

23. Gupta RR, Mahajan BB, Garg G. Chemical peeling Evaluation of glycolic acid in varying concentrations and time intervals, Indian J. Dermatol Venerol Leprol. 2001; 67:28-9.

24. Sarkar R, Kaur C, Bhalla M, Kanwar AJ. The combination of glycolic acid peels with a topical regimen in the treatment of Melasma in dark-skinned patients: a comparative study Dermatol Surg. 2002; 28(9):828-3. 